Article

\title{
Development of a Sustainability Assessment Algorithm and Its Validation Using Case Studies on Cryogenic Machining
}

\author{
Prathamesh Bhat ${ }^{\mathbb{D}}$, Chetan Agrawal ${ }^{\mathbb{D}}$ and Navneet Khanna *(D) \\ Advanced Manufacturing Laboratory, Institute of Infrastructure Technology Research and \\ Management (IITRAM), Ahmedabad 380026, India; prathamesh.bhat.16m@iitram.ac.in (P.B.); \\ chetanagrawal@iitram.ac.in (C.A.) \\ * Correspondence: navneetkhanna@iitram.ac.in; Tel.: +91-70481-43803
}

Received: 31 March 2020; Accepted: 28 April 2020; Published: 30 April 2020

check for updates

\begin{abstract}
This work presents a comprehensive structure for evaluating the sustainability of machining processes. Industries can contribute towards developing a sustainable future by using algorithms that evaluate the sustainability of their processes. Inspired by the literature, the proposed model involves a set of metrics that are critical in evaluating the impact of a process on society, environment, and economy. The flexibility of this model allows decision-makers to use the available responses to identify the most favorable process. The entropy weight method was suggested for objectively calculating the weights of each indicator. A multi-criteria decision-making method i.e., Technique for Order Preference based on Similarity to Ideal Solution (TOPSIS), was used to rank processes in the decreasing order of their sustainability. The proposed algorithm was successfully validated with case studies from the published literature. A MATLAB code was also created so that industries may expeditiously apply this method to evaluate the sustainability of machining processes.
\end{abstract}

Keywords: sustainability evaluation; eco-friendly machining; entropy weight; TOPSIS; cryogenic machining

\section{Introduction}

The manufacturing industry contributed $\$ 14.17$ trillion to the world's GDP in 2018 [1]. Subtractive manufacturing or machining processes such as turning, milling, and drilling have a significant contribution to this value. In 2015, all the UN member states adopted the 2030 Agenda for Sustainable Development (ASD). The seventeen Sustainable Development Goals (SDGs) lie at the heart of this agenda, and all the stakeholders have a strong commitment to achieving these goals. SDG 9 sets out Target 9.4 [2]: "by 2030, upgrade infrastructure and retrofit industries to make them sustainable, with increased resource-use efficiency and greater adoption of clean and environmentally sound technologies and industrial processes, with all countries taking action according to their respective capabilities". An indicator of this target is the $\mathrm{CO}_{2}$ emission per unit of value added. Thus, it has become necessary for manufacturing industries to meet the increasing consumer demand for environmentally sustainable products, satisfy all government regulations, and remain profitable all at the same time.

The three fundamental pillars in sustainability considerations are economy, environment, and society [3]. While establishing the indicators and metrics used to assess sustainability performance, it is essential to take into consideration the four life-cycle stages (pre-manufacturing, manufacturing, use, post-use) [4]. Substantial work has already been done in developing frameworks for sustainability assessment. This article takes inspiration from literature and works towards eliminating flaws in the existing models to present a holistic and objective assessment algorithm. 
The selection of appropriate cooling and lubrication techniques is a critical concern in machining processes [4]. Lu [4] optimized the sustainability performance of cryogenic machining by Process Sustainability Index (ProcSI) methodology using the Genetic Algorithm (GA) based on empirical models. In the proposed model, 65 metrics were organized into six major clusters. The assignment of weights depended on data collected from experts through questionnaires and surveys, and this affected accuracy due to the involvement of personal opinions. Furthermore, when many metrics are involved, obtaining weights through subjective techniques may be time-consuming. For each criterion, scores were assigned by the decision-maker (DM) on a range of 4 to 8 (except for the outliers), which added to the subjectivity.

Hegab et al. [5] proposed an algorithm by extensively defining sustainability indicators, metrics, and measurement methods. Authors have proposed guidelines for sustainable machining processes, which were adapted from literature [6]. In another work, the Total Weighted Sustainability Index (TWSI) was used to find the optimal cutting conditions while machining Inconel-718 with multi-walled carbon nanotubes (MWCNTs) and $\mathrm{Al}_{2} \mathrm{O}_{3}$ nano-fluids [7]. Using the same approach, the sustainability of dry, nanofluid MQL, and flood cooling was investigated during the turning of Steel AISI 1045. After evaluating the alternatives for minimum power utilization and surface finish, it was found that the most sustainable performance was obtained using nanofluid MQL [8]. Kishawy et al. [9] calculated the TWSI of the process alternatives while turning Ti-6Al-4V using MQL and MQL with nano-fluids. In all the studies using TWSI, equal weighting factors were assigned for the criteria in the decision matrix. A strength of this model is that it considers machining quality characteristics in addition to the sustainability metrics during evaluation. Due to this, the guidelines for quantifying criteria values proposed by Hegab et al. [5] were chosen as a reference set in this work. The primary aspects considered in the sustainability evaluation in this work are shown in Figure 1.

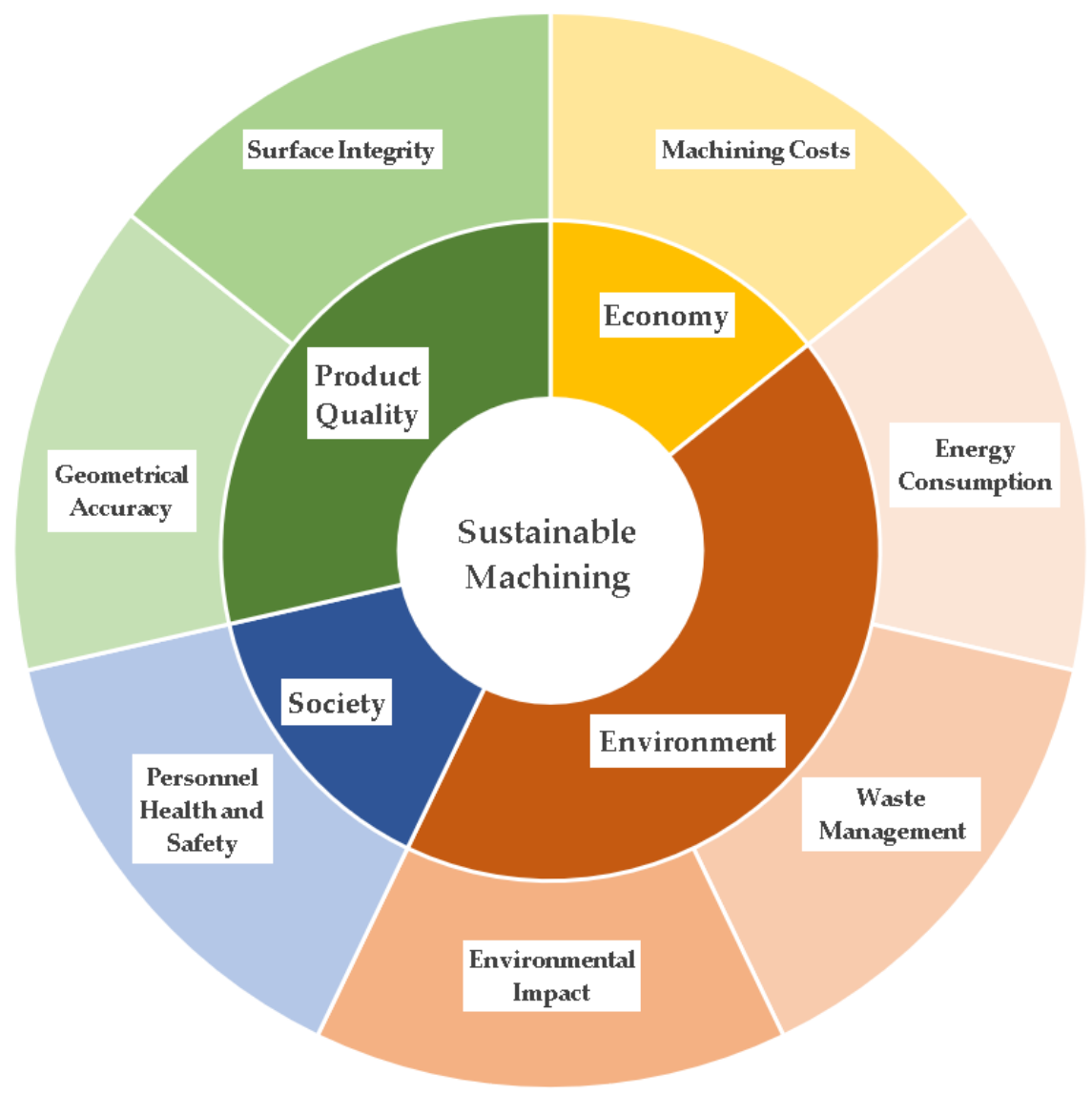

Figure 1. The primary aspects to consider during sustainable machining. 
Liang et al. [10] utilized the Product Sustainability Index (ProdSI) methodology to assess dry machining and High-Pressure Coolant Supply (HPCS) of Ti-6Al-4V. Scores were assigned by the DM for the nine key indicators shown in Table 1. Yip and To [11] carried out the machining of titanium using Single Point Diamond Turning (SPDT) under the influence of a magnetic field. Using ProdSI, it was found that SPDT was more sustainable under the presence of a magnetic field. Mia et al. [12] investigated the effect of dry, MQL, spray, flood, and solid lubricant with a compressed air-cooling system in the turning of hardened AISI 1060 steel using Pugh Matrix environmental approach based on pair-wise comparisons. Bhanot et al. [13] presented a sustainability assessment framework, which focused on the economic and environmental aspects of the process and proposed a social assessment framework for the organization. The case study considered a turning process, involving the machining of an AISI 4140 alloy steel workpiece under wet and dry cooling conditions.

Yan et al. [14] employed objective weighting, in which entropy weight approach and extension theory were used for the assessment using a consistent set of criteria. The sustainability of face milling tests on 45 Steel China was evaluated using a three-tooth tungsten carbide milling cutter. Pellegrini and Ravasio [15] investigated the micro-EDM drilling process in terms of environmental impact, tool wear, dielectric consumption, energy consumption, and machining performance. They proposed a sustainability index to minimize the environmental impact, and machinability indicators were classified accordingly. Khanna et al. [16] studied the machinability of Nimonic 90 using cryogenic assisted turning (CAT) process and cryogenic-ultrasonic assisted turning (CUAT) process in terms of surface roughness, tool wear, energy consumption, and carbon emissions analysis. They reported improved performance under CUAT as compared to the CAT process.

Moreira et al. [17] studied the influence of important process parameters on energy consumption in the CNC vertical milling of BS EN24T alloy using experimentation and Taguchi analysis. A new Multi-swarm Fruit Fly Optimization approach (iMFOA) was used to optimize the energy efficiency of the process. Plessis and Bam [18] developed a framework that can be used by governmental policymakers to compare industries in terms of their opportunity for sustainable development, relying on information released into the public domain. Although it was an industry or sector-level assessment, it was relevant because of the essential points it considered in designing the framework. Kadam and Pawade [19] used ProdSI for assessment during the machining of Inconel-718 under dry, flood coolant, and water vapor cooling and lubrication conditions. Peralta et al. [20] stressed on the need for a global framework to weigh sustainable dimensions equally while doing research and professional practices. They proposed a unified global index for sustainable machine design.

The present work was based on guidelines suggested in the literature. A summary of the assessment frameworks proposed in the literature is presented in Table 1. In the majority of the works, the performance criteria were assigned equal weights. Subjectivity in the selection of weights directly impacts the results of the sustainability assessment. Hence, the weights must be determined objectively. Subjective decisions may only be permitted where necessary, such as in the sub-criteria of personnel health and safety, where it is not feasible to quantify and assign scores to the metrics.

In the context of this work, a machining process is said to be the most sustainable if it achieves a balance between minimizing machining costs, reducing negative impacts on environment and society, and maximizing product quality. It is essential to consider all these points for evaluating sustainability in industries.

This study advances new knowledge and understanding of the sustainability evaluation of machining processes. Apart from this work, the entropy weight method and TOPSIS have not been used in conjunction to evaluate the sustainability of a machining operation. This paper strove to facilitate industry-wide application by retaining the strengths and eliminating the minor weaknesses of previous assessment methods. It provides a robust solution for consistent evaluation. Through case studies, this descriptive work led to the generation of a more precise research problem. 
Table 1. A comparison between the assessment frameworks proposed in the literature.

\begin{tabular}{|c|c|c|c|c|}
\hline Literature Work & Key Indicators & $\begin{array}{l}\text { Assignment of } \\
\text { Weights }\end{array}$ & $\begin{array}{l}\text { Assessment } \\
\text { Method }\end{array}$ & Algorithm \\
\hline $\mathrm{Lu}[4]$ & $\begin{array}{ll}\text { - } & \text { Manufacturing Cost } \\
\text { - } & \text { Energy Consumption } \\
\text { - } & \text { Waste Management } \\
\text { - } & \text { Environmental Impact } \\
\text { - } & \text { Personal Health } \\
\text { - } & \text { Operator Safety }\end{array}$ & $\begin{array}{l}\text { Subjective: } \\
\text { Depends on } \\
\text { personal preference } \\
\text { obtained from } \\
\text { questionnaires and } \\
\text { surveys }\end{array}$ & $\begin{array}{c}\text { Process } \\
\text { Sustainability } \\
\text { Index (ProcSI) }\end{array}$ & $\begin{array}{l}\text { Genetic } \\
\text { Algorithm }\end{array}$ \\
\hline Yan et al. [14] & $\begin{array}{ll}\text { - } & \text { Energy Consumption } \\
\text { - } & \text { Cutting } \\
\text { - } & \text { Fluid Consumption } \\
& \text { Oubricant } \\
\text { - } & \text { Tool Life } \\
\text { - } & \text { Machining Time } \\
\text { - } & \text { Surface Roughness } \\
\text { - } & \text { Cutting Noise }\end{array}$ & $\begin{array}{l}\text { Objective: Entropy } \\
\text { Weight Method }\end{array}$ & $\begin{array}{l}\text { Comprehensive } \\
\text { Correlation Degree }\end{array}$ & $\begin{array}{l}\text { Extension } \\
\text { Theory }\end{array}$ \\
\hline $\begin{array}{l}\text { Kadam and } \\
\text { Pawade [19] }\end{array}$ & $\begin{array}{ll}\text { - } & \text { Generation and Supply } \\
\text { - } & \text { Operator Health and } \\
\text { - } & \text { Safety, Emissions } \\
\text { - } & \text { Part Cleaning } \\
\text { - } & \text { Scrap Disposal } \\
\text { - } & \text { Surface Roughness } \\
\text { - } & \text { Residual Stresses }\end{array}$ & Absent & $\begin{array}{l}\text { Product } \\
\text { Sustainability } \\
\text { Index (PSI) }\end{array}$ & $\begin{array}{l}\text { Simple Average } \\
\text { Method }\end{array}$ \\
\hline Hegab et al. [5] & $\begin{array}{l}\text { Employed and elaborated on } \\
\text { the five major metrics } \\
\text { proposed in [4] }\end{array}$ & $\begin{array}{l}\text { Subjective: Equal } \\
\text { Weighting }\end{array}$ & $\begin{array}{l}\text { Total Weighted } \\
\text { Sustainable Index } \\
\text { (TWSI) }\end{array}$ & $\begin{array}{c}\text { Heuristic } \\
\text { Approach } \\
\text { (multi-objective } \\
\text { solver) }\end{array}$ \\
\hline Liang et al. [10] & $\begin{array}{ll}\text { - } & \text { Environment Effect } \\
\text { - } & \text { Operator Health } \\
\text { - } & \text { Workpiece Cleaning } \\
\text { - } & \text { Coolant Recycling } \\
& \text { and Disposal } \\
\text { - } & \text { Coolant Cost } \\
\text { - } & \text { Tool Cost } \\
\text { - } & \text { Processing Efficiency } \\
\text { - } & \text { Energy Consumption } \\
\text { - } & \text { Surface Roughness }\end{array}$ & Absent & $\begin{array}{l}\text { Product } \\
\text { Sustainability } \\
\text { Index (PSI) }\end{array}$ & $\begin{array}{l}\text { Simple Average } \\
\text { Method }\end{array}$ \\
\hline Mia et al. [12] & $\begin{array}{ll}\text { - } & \text { Environmental Effect } \\
\text { - } & \text { Operator Health } \\
\text { - } & \text { Coolant Cost } \\
\text { - } & \text { Coolant Recycling } \\
& \text { and Disposal } \\
\text { - } & \text { Part Cleaning } \\
\text { - } & \text { Surface Roughness } \\
\text { - } & \text { Cutting Temperature }\end{array}$ & $\begin{array}{l}\text { Subjective: Equal } \\
\text { Weighting }\end{array}$ & $\begin{array}{l}\text { Pugh Matrix } \\
\text { Approach }\end{array}$ & $\begin{array}{l}\text { Pair-wise } \\
\text { Comparison }\end{array}$ \\
\hline Present Work & $\begin{array}{l}\text { Recommends the use of } \\
\text { indicators and measurement } \\
\text { methods proposed in [5] as a } \\
\text { reference set }\end{array}$ & $\begin{array}{l}\text { Objective: Entropy } \\
\text { Weight Method }\end{array}$ & $\begin{array}{c}\text { Relative } \\
\text { Sustainability of } \\
\text { Process (RSP) }\end{array}$ & TOPSIS \\
\hline
\end{tabular}




\section{Sustainability Assessment Algorithm}

\subsection{Decision-Making Process}

When the best alternative must be selected from amongst a finite set and a comparison between conflicting criteria is involved, the decision-making process falls under the purview of multi-attribute decision-making (MADM). The entropy weight method and TOPSIS were selected for this application due to their inherent advantages. Since alternate methods involving pairwise comparisons such as Analytic Hierarchy Process (AHP) and ELECTRE involve subjectivity of the decision-makers; they were not been employed. An effort was made to minimize the time to decide by avoiding such techniques such as ELECTRE, or the reiteration of pairwise comparisons that may occur in case of uncertainty and inconsistency while using AHP.

Consider a decision-making problem involving $m$ alternatives with $n$ criteria to be used in the comparison. The matrix form can be expressed as:

$$
D=\left[\begin{array}{cccc}
x_{11} & x_{12} & \ldots & x_{1 n} \\
x_{21} & x_{22} & \ldots & x_{2 n} \\
\vdots & \vdots & \ddots & \vdots \\
x_{m 1} & x_{m 1} & \ldots & x_{m n}
\end{array}\right]
$$

The rows represent the $m$ alternatives that the decision-maker has to choose from, and the columns represent the $n$ criteria against which the performance of the alternatives is measured. $x_{m n}$ represents the performance of the alternative $A_{m}$ under the criterion $C_{n}$. There are two principal types of criteria: benefit criteria (higher-the-better) and cost criteria (lower-the-better). The weights of the $n$ criteria are elements of the set $W$.

$$
W=\left(w_{1}, w_{2}, \ldots, w_{n}\right)
$$

The key steps of the entropy weight method and TOPSIS are summarized in the subsequent sections.

\subsubsection{Entropy Weight Method}

The entropy weight method was used to calculate the weights of the performance criteria to eliminate errors and discrepancies that may occur while using pure subjective weighting [21].

Step 1: Normalization of the decision matrix. The elements of the decision matrix must be processed into non-dimensional criterion to eliminate the influence of their dimension, and permit comparison between different metrics. If there are $m$ alternatives and $n$ criteria,

$$
r_{i j}=\frac{x_{i j}}{\sum_{i=1}^{m} x_{i j}} \forall j \in[1, n]
$$

This generates the normalized decision matrix:

$$
R=\left(r_{i j}\right)_{m \times n} \forall i \in[1, m], j \in[1, n]
$$

Step 2: Computation of the entropy.

$$
e_{j}=-\frac{1}{\ln (m)} \sum_{i=1}^{m} r_{i j} \ln \left(r_{i j}\right) \forall i \in[1, m], j \in[1, n]
$$

Step 3: Computation of the weight vector. The entropy weight can be evaluated as

$$
w_{j}=\frac{1-e_{j}}{\sum_{j=1}^{n} 1-e_{j}} \forall j \in[1, n]
$$




\subsubsection{Technique for Order Preference Based on Similarity to Ideal Solution (TOPSIS)}

After deriving the weights of the criteria, TOPSIS was used to rank the alternatives. TOPSIS was developed by Hwang and Yoon [22] to find a solution that is closest to the positive ideal and farthest from the negative ideal. The main steps are described below:

Step 1: Calculation of the normalized decision matrix. The scores in each column are converted into numbers based on the normalized scale.

$$
n_{i j}=\frac{x_{i j}}{\sqrt{\sum_{i=1}^{m} x_{i j}^{2}}}, \forall j \in[1, n]
$$

Step 2: Calculation of the weighted normalized decision matrix. It is calculated using the following formula, using the weights from Equation (6):

$$
V_{i j}=w_{j} n_{i j}, \forall i \in[1, m], j \in[1, n]
$$

Step 3: Determination of the positive ideal and negative ideal solutions. If the criterion is higher-the-better, the positive ideal solution is its maximum value and the negative ideal solution is its minimum value. The opposite is true for a lower-the-better criterion. The solutions take the form:

$$
\begin{gathered}
V_{j}^{+}=\left(v_{1}^{+}, v_{2}^{+}, \ldots, v_{n}^{+}\right)=\left(\left(\max _{i j} \mid j \in I\right),\left(\min _{i j} \mid j \in J\right)\right) \\
V_{j}^{-}=\left(v_{1}^{-}, v_{2}^{-}, \ldots, v_{n}^{-}\right)=\left(\left(\min v_{i j} \mid j \in I\right),\left(\max _{i j} \mid j \in J\right)\right)
\end{gathered}
$$

where the set $I$ is associated with benefit criteria and set $J$ with cost criteria.

Step 4: Calculation of the separation measures from the positive ideal solution and the negative ideal solution:

$$
\begin{aligned}
& d_{i}^{+}=\sqrt{\sum_{j=1}^{n}\left(V_{i j}-V_{j}^{+}\right)^{2}}, \forall i \in[1, m] \\
& d_{i}^{-}=\sqrt{\sum_{j=1}^{n}\left(V_{i j}-V_{j}^{-}\right)^{2}}, \forall i \in[1, m]
\end{aligned}
$$

Step 5: Calculation of the relative closeness to the positive ideal solution. The relative closeness of the $i_{t h}$ alternative to the positive ideal solution is

$$
R_{i}=\frac{d_{i}^{-}}{d_{i}^{-}+d_{i}^{+}}, \forall i \in[1, m] .
$$

The value of $R_{i}$ ranges from 0 to 1 . A higher value indicates that the alternative is farther from the negative ideal, and closer to the positive ideal. Hence, a higher value is desired.

If the set of performance criteria comprises metrics from the recommended sustainability assessment model, the value of $R_{i}$ obtained using TOPSIS is called the Relative Sustainability of Process (RSP), since it signifies the sustainability of a process relative to its alternatives.

Step 6: Ranking of the alternatives in descending order: The set of alternatives are ranked in decreasing order of their RSP values. The alternative with the highest RSP is the most desirable since it is the most sustainable. It must be noted that the number of steps in TOPSIS is fixed irrespective of the number of candidate processes. A flowchart of the sustainability assessment methodology is presented in Figure 2. 


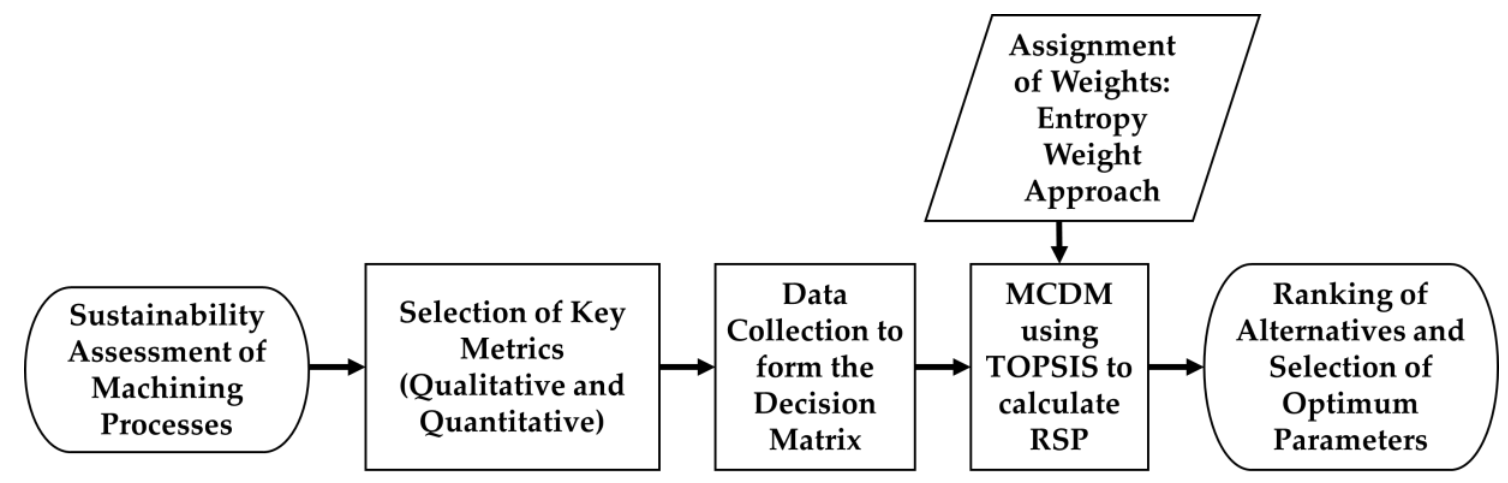

Figure 2. Flowchart of the sustainability assessment methodology.

\section{Empirical Validation}

Three case studies from the literature were presented to validate the effectiveness of the suggested algorithm. Cooling and lubrication techniques have a major influence on the process performance and sustainability by affecting cost, operator safety, and ease in the disposal. An effort was made to involve studies related to cryogenic machining to verify that the proposed method could confirm the findings that were stated in the literature, that is-to confirm if cryogenic machining is the most sustainable alternative at the given cutting parameters.

The present case studies serve as a useful tool for exploratory investigation. Critical cases or studies having pertinent data on the subject of sustainable machining were found in the literature for this descriptive research. Selecting a random experiment was not suitable for this study since the objective was to obtain the most amount of information in the form of performance characteristics. The results of the study were then compared with its exemplars, which led to the generation of a hypothesis. It provides a new perspective and helped refine the issue for a more systematic investigation.

The method of processing data obtained from the literature is elaborated below. All the relevant files 'upload.m', 'topsis.m', 'Input.xlsx', and 'Output.xlsx' have been developed for this application and uploaded to the data repository Dryad. The link to the data repository may be obtained in the Supplementary Materials section below.

- Data from the selected papers were compiled in a spreadsheet 'Input.xlsx' in Microsoft Excel 2016. The decision-making matrix was in the form as shown in Equation (1): rows representing alternatives and columns representing criterion. Benefit criteria were assigned a value of ' 1 ', and cost criteria were assigned a value of ' -1 ' in the criteria sign row.

- MATLAB R2019a was used to open 'upload.m'. After being run, this code collected data from 'Input.xlsx'.

- Following this, the code 'topsis.m' was run in order to display the processed results in the second spreadsheet, 'Output.xlsx'.

- The alternative with the highest RSP was identified as the best alternative from the sustainability viewpoint.

Assuming that all industry regulations and standards are adhered to, a decision-maker in a machining industry may choose the most suitable alternative for implementation from amongst the processes with high RSP values.

\subsection{Case Study 1}

Mia et al. [23] studied a range of machining responses in the turning of Ti-6Al-4V alloy using the Taguchi $L_{27}$ full factorial orthogonal array design. The cutting parameters were: cutting speed $\left(v_{c}\right)$, feed $\left(f_{r}\right)$, and cooling environment (dry, liquid nitrogen $\left(\mathrm{LN}_{2}\right)$ mono-jet nozzle and $\mathrm{LN}_{2}$ dual-jet nozzle). The responses included: surface roughness, material removal rate, interface temperature, specific 
cutting energy, and main cutting force. Grey Relational Analysis (GRA) was used in the optimization of parameters.

After compiling the available data according to the specified guidelines, the machining responses were processed using the entropy weight method and TOPSIS as described above to obtain the Relative Sustainability of Process (RSP) for each alternative. The criteria included in the assessment were chip-tool temperature, surface roughness, specific cutting energy, and environmental impact due to electricity consumption $\left(E n_{e}\right)$ in $\mathrm{kg}-\mathrm{CO}_{2} / \mathrm{mm}^{3}$.

By analyzing the results shown in Figure 3, experiment number 21 was found to be the most sustainable alternative. This corresponds to the conditions: $v_{c}=140 \mathrm{~m} / \mathrm{min}, f_{r}=0.12 \mathrm{~mm} / \mathrm{rev}$ and dual-jet impingement of $\mathrm{LN}_{2}$. The optimal results have been compared in Table 2.

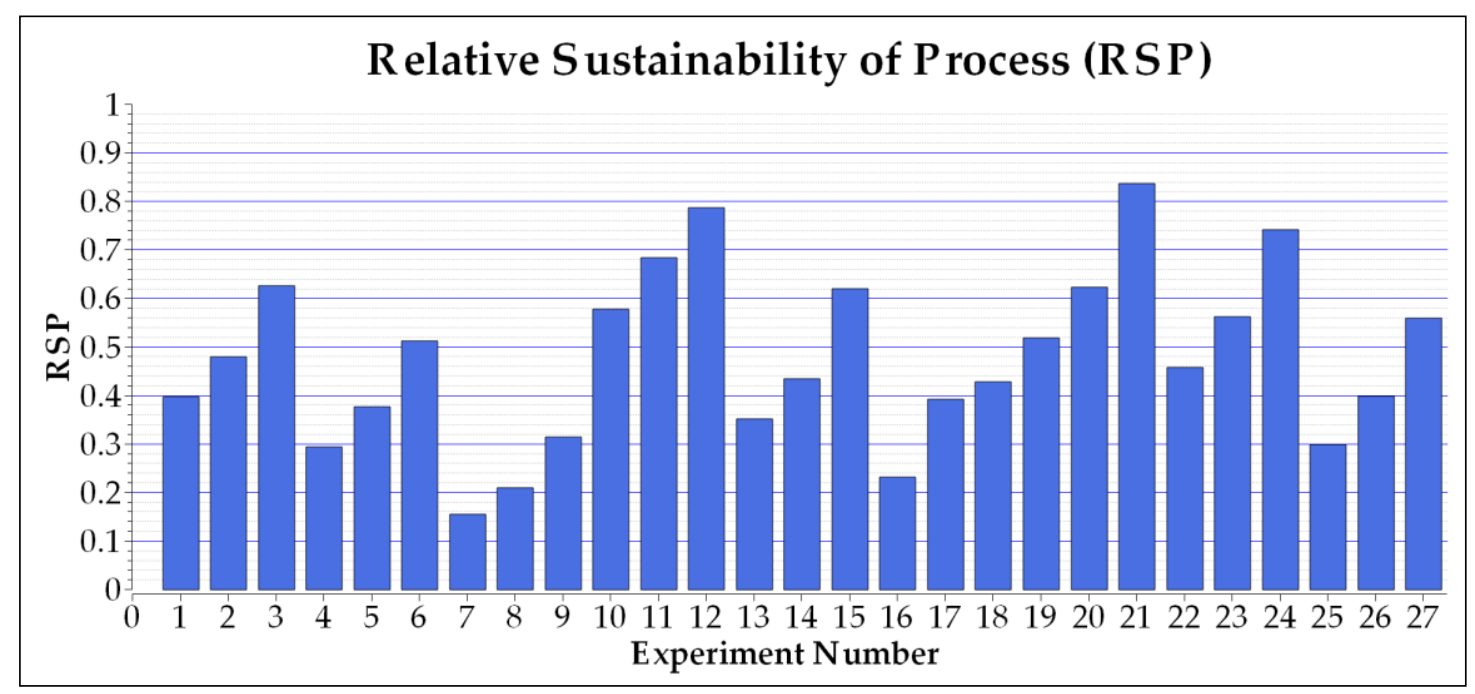

Figure 3. RSP of the alternatives in Mia et al. [23].

Table 2. The machining responses of the best alternative as predicted by the proposed algorithm vs. the optimal results stated in the literature.

\begin{tabular}{ccc}
\hline Machining Response & Result of the Algorithm & Optimal Result in Literature \\
\hline Main Cutting Force $(\mathrm{N})$ & 647.45 & 647.45 \\
Chip-tool Interface Temperature $\left({ }^{\circ} \mathrm{C}\right)$ & 1100 & 1100 \\
Surface Roughness $(\mu \mathrm{m})$ & 1.23 & 1.23 \\
Specific Cutting Energy $\left(\mathrm{J} / \mathrm{mm}^{3}\right)$ & 4.62 & 4.62 \\
Material Removal Rate $\left(\mathrm{mm}^{3} / \mathrm{min}\right)$ & 19.6 & 19.6 \\
\hline
\end{tabular}

There is a perfect match between the results suggested by this algorithm and those published in the literature. The second and third best alternatives, i.e., experiment numbers 12 and 24 also correspond to the use of dual-jets in the turning process. This suggests that when cryogenic fluid impinges on both the flank and rake surfaces of the tungsten carbide cutting insert, favorable responses are obtained. Compared to the GRA used in the original work, there has been no subjectivity in this decision-making process, since weights have been assigned by the entropy weight method.

\subsection{Case Study 2}

Sivaiah and Chakradhar [24] machined 17-4 PH stainless steel at varying depth of cut settings using Kennametal SNMG120408 MP cutting inserts. The results of turning with $\mathrm{LN}_{2}$ were compared with dry, wet, and minimum-quantity lubrication (MQL) environments. The $f_{r}$ and $v_{c}$ were kept constant in the process. The parameters investigated were: surface integrity, cutting temperature, chip morphology and tool wear (flank and rake face). 
To obtain raw data, the line plots from the literature were digitized using an open-source program ScanIt 2.07, a product of AmsterCHEM. The data obtained after digitization may be found in Table A1, Appendix A. After collecting data, the performance characteristics were processed to obtain the RSP as described previously. In coherence with the guidelines, the operational safety index to express toxic chemical exposure $\left(O S_{t c}\right)$, i.e., for dry-1, cryogenic $-1, \mathrm{MQL}-2$, wet- 3 was used in addition to the previous four criteria.

Sivaiah and Chakradhar [24] found that cryogenic cooling provided the best performance characteristics compared to dry, wet, and MQL conditions. The use of $\mathrm{LN}_{2}$ outperformed the rest in terms of tool wear and surface roughness. The proposed algorithm is validated since it provides the same results. From Figure 4, it can be observed that experiments 16-20 surpass the rest in terms of RSP. These experiments correspond to the use of cryogenic cooling in the turning process. Experiment number 16 provides the highest RSP and was conducted at the lowest depth of cut $\left(a_{p}=0.2 \mathrm{~mm}\right)$. The performance characteristics at this condition are: $\mathrm{T}=24{ }^{\circ} \mathrm{C}$, tool flank wear $=55 \mu \mathrm{m}$, tool rake wear $=62 \mu \mathrm{m}$ and $R_{a}=1.31 \mu \mathrm{m}$.

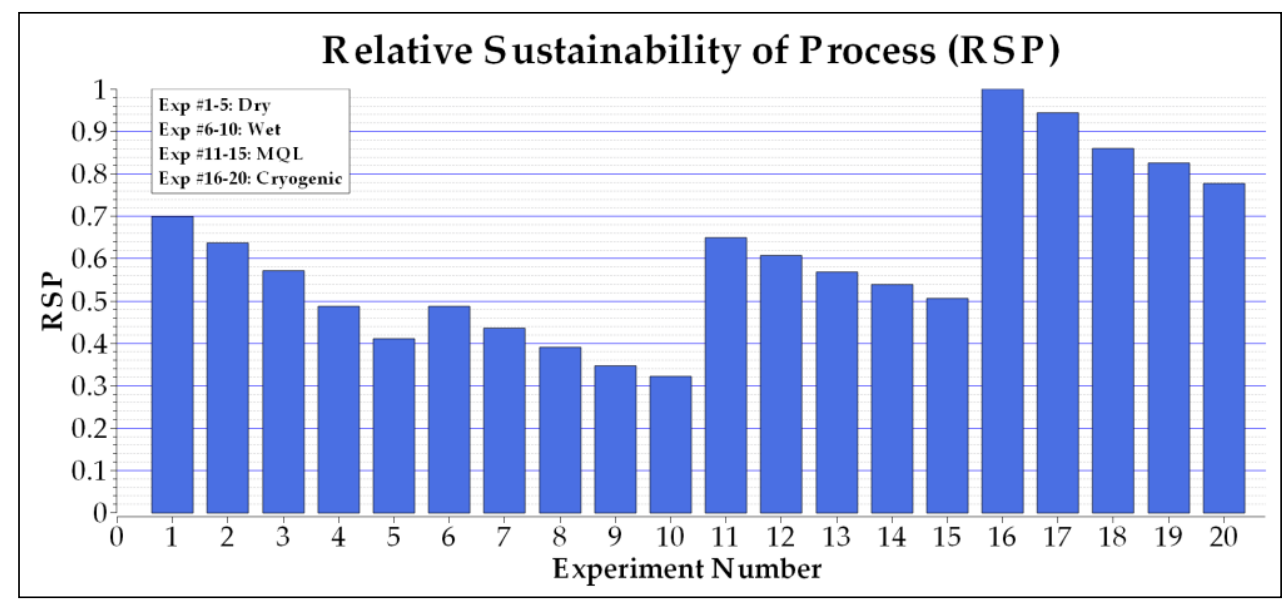

Figure 4. RSP of the alternatives in Sivaiah and Chakradhar [24].

\subsection{Case Study 3}

Shokrani et al. [25] investigated the effects of $\mathrm{LN}_{2}$ as a coolant in the CNC end milling of Ti-6Al-4V compared to the conventional machining alternatives (dry and flood cooling). An $L_{9}$ orthogonal array design of experiments was used. The machinability metrics measured were: power consumption, surface roughness, specific cutting energy, and tool life (machining length and volume of material removed). The key cutting parameters were: $a_{p}, v_{c}$, machining environment, and $f_{r}$. The signal-to-noise (SN) ratio was used to identify the optimum level for end milling of the titanium alloy.

Following the collection of data, the machining metrics were processed to obtain the RSP values. The criteria included in the analysis were surface roughness, the volume of material removed, specific cutting energy, $E n_{e}$, and $O S_{t c}$.

According to the literature, cryogenic machining provided the highest mean $\mathrm{SN}$ ratio across a majority of the machining responses. This indicated that cryogenic cooling provided the most suitable environment for improving the machinability of Ti- $6 \mathrm{Al}-4 \mathrm{~V}$ at the cutting parameters used. Figure 5 presents the results obtained using the proposed algorithm and it demonstrates that experiment number 7 has the highest RSP, followed by experiment 5 . The machining metrics in experiment 7 are: surface roughness $=0.26 \mu \mathrm{m}$, machining length $=3000 \mathrm{~mm}$, volume of material removed $=60,000 \mathrm{~mm}^{3}$, power consumption $=1479 \mathrm{~W}$ and specific energy $=28.1 \mathrm{~J} / \mathrm{mm}^{3}$. A cryogenic environment was used in experiment number 7 , and the findings coincide with those in the published literature. Thus, the proposed method has been effective in suggesting the experiment with the highest overall sustainability, productivity, and quality. 


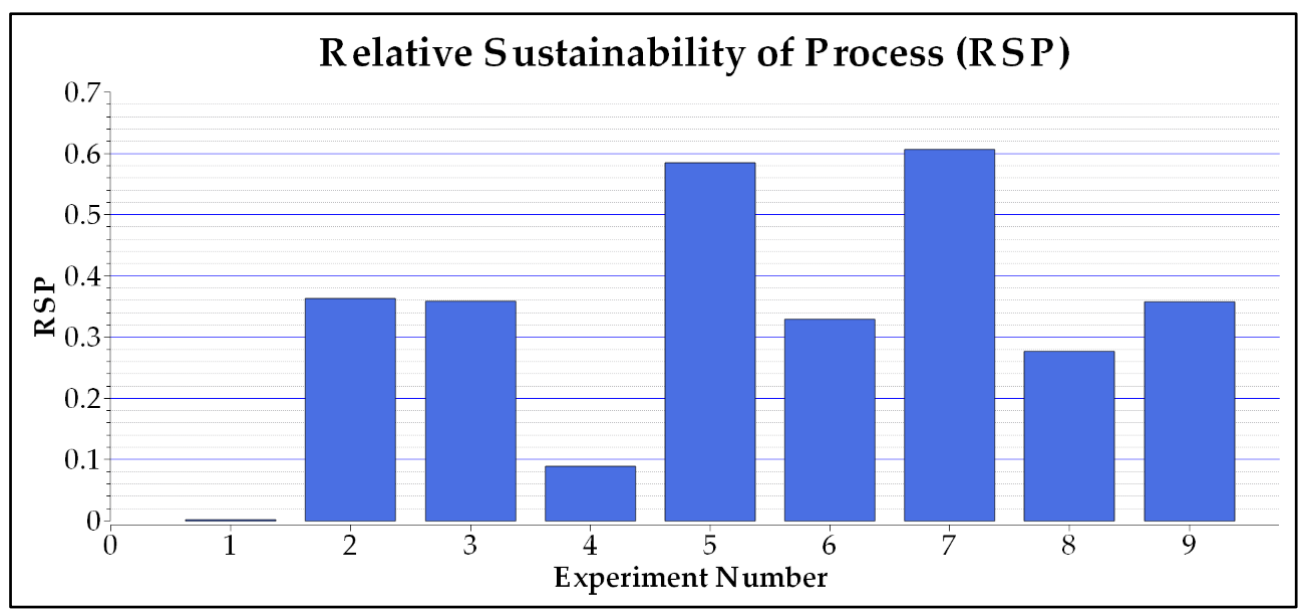

Figure 5. RSP of the alternatives in Shokrani et al. [25].

\subsection{Case Study 4}

Khanna and Agrawal [26] conducted the turning operation on Ti-6Al-4V in dry and cryogenic machining environments with a coated carbide turning insert. Hybrid DoE was used with the process parameters namely $f_{r}, v_{c}$, and $a_{p}$. The measured responses included: power consumption, surface roughness, and resultant force. ANOVA (Analysis of Variance) was used to understand the contribution of each process parameter to the values of machining responses.

Data were collected in accordance with the recommended guidelines. In the original work, only the power consumption during machining was taken into consideration. To truly evaluate the sustainability of cryogenic machining, the energy consumption associated with the generation of liquid nitrogen has also been taken into consideration in this study. This value was obtained from the machining time, the flow rate of $\mathrm{LN}_{2}$, the density of $\mathrm{LN}_{2}$ at $1.5 \mathrm{MPa}$ and $-196{ }^{\circ} \mathrm{C}$, and the electrical energy required to produce $\mathrm{LN}_{2}$. The electrical energy required to liquefy nitrogen typically ranges from $1800-1976 \mathrm{~kJ} / \mathrm{kg}[27,28]$. In this case study, this value was taken as $1850 \mathrm{~kJ} / \mathrm{kg}$. The RSP value was calculated from the criteria as described above, using: surface roughness, total energy consumption, and $E n_{e}$ in $\mathrm{kg}-\mathrm{CO}_{2}$.

The results in this work provided evidence to support the advantages of cryogenic machining with respect to surface properties. From Figure 6, it can be seen that the proposed algorithm for sustainability analysis suggests that dry machining consistently outperforms cryogenic machining. Experiment number 6 (dry) has the highest RSP value, and is performed at the conditions: $v_{c}=69.94$ $\mathrm{m} / \mathrm{min}, f_{r}=0.333 \mathrm{~mm} / \mathrm{rev}$ and $a_{p}=0.5 \mathrm{~mm}$. It can be observed from Figure 6 that although cryogenic machining is a competitive alternative, it is not the most sustainable. This is because, in addition to the energy required during machining, the energy consumption related to the production of liquefied nitrogen has been considered. While cryogenic machining results in improved surface properties, it has not proven to be a more sustainable alternative at all cutting conditions. This algorithm was used to assess experiments from a holistic sustainability viewpoint. After studying the results, the final choice of the experiment to be conducted lies with the decision-maker. 


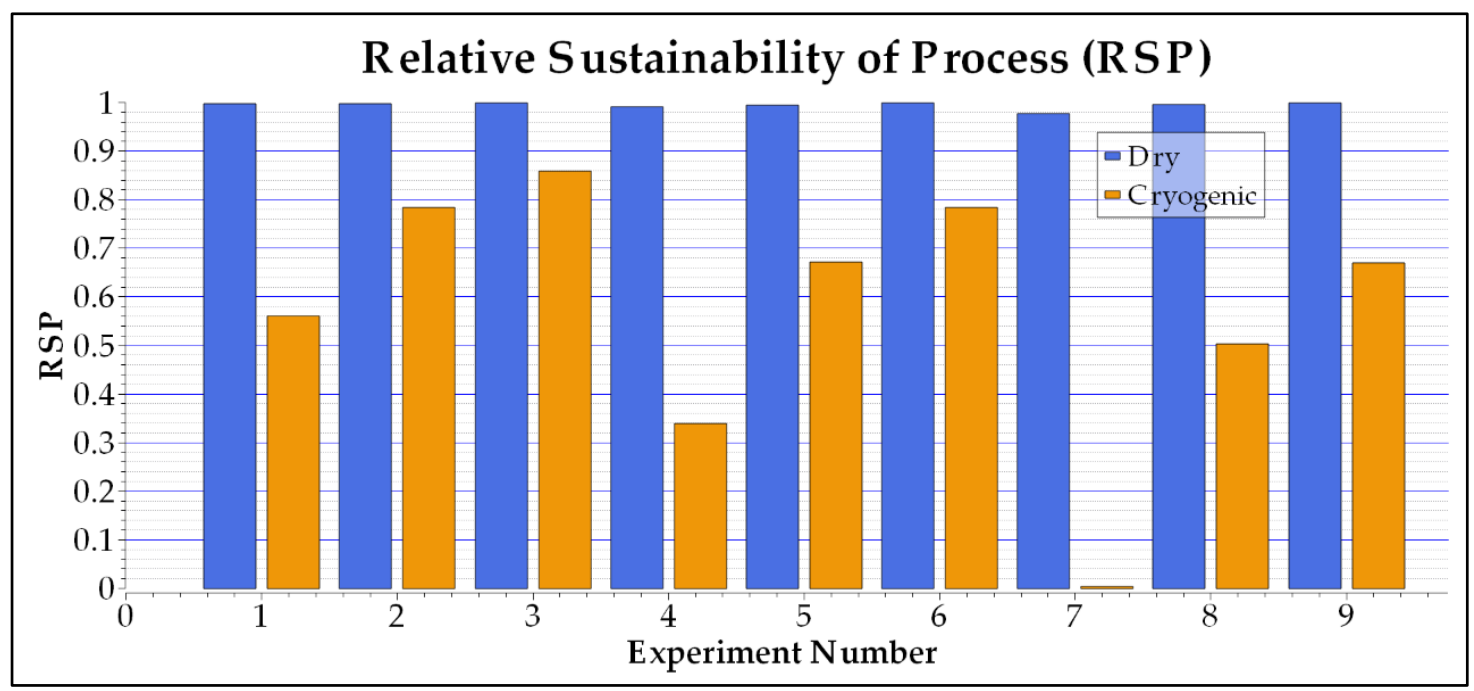

Figure 6. RSP of the alternatives in Khanna and Agarwal [26].

\section{Discussion}

Since the data available in the case studies was limited, it was only possible to evaluate sustainability based on information in the existing critical cases. However, for a thorough assessment, it is suggested that at least one metric be used from each section of the pie shown in Figure 1.

Although the case studies have validated the utility of this code in machining industries, the range of applications of this technique is not limited to this field or subject. The resources provided in the Supplementary Materials section may be used whenever an objective decision has to be made amongst alternatives with conflicting criteria.

Mia et al. [23] stated that dry machining of Ti-6Al-4V above a $v_{c}$ of $100 \mathrm{~m} / \mathrm{min}$ is difficult. In the work, experiments were conducted from $80-140 \mathrm{~m} / \mathrm{min}$ using dry and cryogenic cooling conditions. The results showed that the use of dual-jets of $\mathrm{LN}_{2}$ provided the ideal responses at the highest $v_{C}$ $(140 \mathrm{~m} / \mathrm{min})$. The authors of this work find it imperative to state that although three case studies indicate that cryogenic machining is the most sustainable alternative, it cannot be inferred that this is true for all cutting conditions.

For cryogenic cooling to provide the most sustainable result in this algorithm, the benefits (reduction in surface roughness, dimensional deviation, etc.) must outweigh the costs (increase in cutting forces, power consumption, etc.) This generally occurs when dry machining fails to provide the desired results at high cutting conditions. During validation in papers (Table 3) such as Khanna and Agrawal [26], it was found that although cryogenic machining offered certain advantages, dry machining was overall a more sustainable alternative. The hypothesis is that this occurred because the experiments in these papers were performed at conditions at which the full potential of the cooling provided by the liquefied gas was not realized. At those cutting conditions, cryogenic cooling turned out to be a less sustainable alternative because of the increase in power consumption and cutting force compared to dry machining.

Numerous works in the literature have tested whether cryogenic machining offers advantages compared to its alternative cooling and lubrication techniques. The published results are a testament to the benefits provided by the use of liquefied gases. This work objectively assessed multiple cases from the viewpoint of sustainability. After shifting the focus from one or two outputs, to the multiple indicators of sustainability, a case revealed that there is potential for its alternatives to be more sustainable at certain cutting conditions. This analysis has led to the formulation of a new research question-'At what cutting conditions is cryogenic machining more sustainable compared to its alternatives?' 
Table 3. Validation of the algorithm using critical cases from the literature.

\begin{tabular}{|c|c|c|c|c|c|}
\hline $\begin{array}{l}\text { Source of Data } \\
\text { for Case Study }\end{array}$ & $\begin{array}{c}\text { Criteria Used in Present } \\
\text { Assessment }\end{array}$ & $\begin{array}{c}\text { Energy Associated with } \\
\text { Coolant/Lubricant } \\
\text { Production }\end{array}$ & $\begin{array}{l}\text { Environments } \\
\text { Compared }\end{array}$ & $\begin{array}{l}\text { Environment } \\
\text { with Highest } \\
\text { RSP }\end{array}$ & $\begin{array}{l}\text { Additional } \\
\text { Comments }\end{array}$ \\
\hline $\begin{array}{l}\text { 1: Mia et al. } \\
{[23]}\end{array}$ & $\begin{array}{ll}\text { - } & \text { Chip-tool temperature } \\
\text { - } & \text { Surface roughness } \\
\text { - } & \text { Specific cutting energy } \\
\text { - } & \text { Environmental impact } \\
& \text { due to electricity } \\
\text { consumption }\left(E n_{e}\right)\end{array}$ & $\begin{array}{l}\text { Not included in the } \\
\text { present evaluation. }\end{array}$ & $\begin{array}{ll}- & \text { Dry } \\
\text { - } & \mathrm{LN}_{2} \\
& \text { mono-jet nozzle } \\
\text { - } & \mathrm{LN}_{2} \\
& \text { dual-jet nozzle }\end{array}$ & $\begin{array}{l}\mathrm{LN}_{2} \text { dual-jet } \\
\text { nozzle }\end{array}$ & $\begin{array}{l}\text { Both evaluation } \\
\text { methods found } \\
\text { alternative } 13 \text { to be } \\
\text { the most sustainable. }\end{array}$ \\
\hline $\begin{array}{l}\text { 2: Sivaiah and } \\
\text { Chakradhar } \\
\text { [24] }\end{array}$ & $\begin{array}{ll}\text { - } & \text { Surface integrity } \\
\text { - } & \text { Cutting temperature } \\
\text { - } & \text { Tool wear (flank and } \\
\text { - } & \text { rake face) } \\
\text { OS } & \end{array}$ & $\begin{array}{l}\text { Not included in the } \\
\text { present evaluation. }\end{array}$ & $\begin{array}{ll}- & \text { Dry } \\
- & \text { Wet } \\
- & \mathrm{MQL} \\
- & \text { Cryogenic } \\
& \left(\mathrm{LN}_{2}\right)\end{array}$ & Cryogenic & $\begin{array}{l}\text { The work's aim was } \\
\text { not MADM. } \\
\text { Nevertheless, the } \\
\text { same trend was } \\
\text { identified using the } \\
\text { proposed algorithm } \\
\text { (Figure 4). }\end{array}$ \\
\hline $\begin{array}{l}\text { 4: Khanna and } \\
\text { Agarwal [26] }\end{array}$ & $\begin{array}{ll}\text { - } & \text { Surface roughness } \\
\text { - } & \text { Total } \\
\text { energy consumption } \\
\text { - Environmental impact } \\
\text { due to energy } \\
\text { consumption }\left(E n_{e}\right)\end{array}$ & $\begin{array}{l}\text { Included in the present } \\
\text { evaluation. }\end{array}$ & $\begin{array}{ll}\text { - } & \text { Dry } \\
\text { - } & \text { Cryogenic }\end{array}$ & Dry & $\begin{array}{l}\text { Cryogenic } \\
\text { machining offered } \\
\text { improvements in } \\
\text { product quality, but } \\
\text { the inclusion of } \\
\text { energy required to } \\
\text { liquefy nitrogen led } \\
\text { to the suggestion } \\
\text { that dry machining is } \\
\text { a more sustainable } \\
\text { environment. }\end{array}$ \\
\hline
\end{tabular}

\section{Conclusions}

This article aimed to act as an aid in the decision-making process for managers, engineers, and designers in machining industries. Since it is becoming increasingly essential to adopt green manufacturing practices, this paper attempted to bridge the gap between theory and practice by outlining critical indicators for evaluating sustainability and proposing a working model. The entropy weight technique and TOPSIS were used since they are intuitive concepts that are computationally simple. The MATLAB code developed specifically for this purpose may be used to rank and select the most favorable alternative according to feasibility and preference. The case study approach in this article has proven to be a useful tool for satisfying the two-pronged approach of this work: it validates the functionality of this decision-making tool by confirming the results and trends with those of its exemplars, and it generates a new hypothesis for further study. The proposed method is a simple and holistic solution to improve decision-making for sustainability.

Supplementary Materials: The MATLAB programs and Excel workbooks have been uploaded to the data repository: Publisher: Dryad. Reviewer URL: https://datadryad.org/stash/share/RHUC2su4YaH79w85NlamNpU pgAqjY64GZEiT95jXzxk. Citation: Bhat, Prathamesh; Agrawal, Chetan; Khanna, Navneet (2020), Development of a Sustainability Assessment Algorithm and its Validation for Machining Processes, Dataset, https://doi.org/10. 5061/dryad.xd2547ddg.

Author Contributions: Conceptualization-P.B., C.A., N.K.; methodology-P.B., C.A., N.K.; software-P.B.; validation-P.B., C.A., N.K.; formal analysis-C.A., N.K.; investigation-P.B., C.A., N.K.; resources-N.K.; data curation-P.B., N.K.; writing—original draft preparation-P.B.; writing-review and editing-C.A., N.K.; visualization-P.B., N.K.; supervision-N.K.; project administration-N.K. All authors have read and agreed to the published version of the manuscript.

Funding: The authors would like to thank the SERB-DST, Government of India, for the financial support given under the Project (ECR/2016/000735).

Conflicts of Interest: The authors declare no conflict of interest. 


\section{Nomenclature}

$\begin{array}{ll}\text { AHP } & \text { Analytic Hierarchy Process } \\ a_{p} & \text { Depth of cut }(\mathrm{mm}) \\ \text { ELECTRE } & \text { Elimination Et Choix Traduisant la Realité } \\ E n_{e} & \text { Environmental impact due to electricity consumption } \\ f_{r} & \text { Feed rate }(\mathrm{mm} / \mathrm{rev}) \\ \mathrm{LN}_{2} & \text { Liquid nitrogen } \\ \text { MADM } & \text { Multi-attribute decision-making } \\ \text { MQL } & \text { Minimum quantity lubrication } \\ \text { OS } & \text { Operational safety index to express toxic chemical exposure } \\ R_{a} & \text { Average surface roughness }(\mu \mathrm{m}) \\ \text { RSP } & \text { Relative Sustainability of Process } \\ \text { TOPSIS } & \text { Technique for Order Preference Based on Similarity to Ideal Solution } \\ v_{c} & \text { Cutting speed (m/min) }\end{array}$

\section{Appendix A}

Table A1. Raw data obtained after digitizing the graphs in Sivaiah and Chakradhar [24].

\begin{tabular}{|c|c|c|c|c|c|c|}
\hline Environment & Experiment & $\begin{array}{l}\text { Depth of } \\
\text { Cut (mm) }\end{array}$ & $\begin{array}{c}\text { Temperature } \\
\left({ }^{\circ} \mathrm{C}\right)\end{array}$ & $\begin{array}{l}\text { Tool Flank } \\
\text { Wear }(\mu \mathrm{m})\end{array}$ & $\begin{array}{l}\text { Tool Rake } \\
\text { Wear }(\mu \mathrm{m})\end{array}$ & $\begin{array}{c}\text { Surface } \\
\text { Roughness }(\mu \mathrm{m})\end{array}$ \\
\hline \multirow{5}{*}{ Dry } & 1 & 0.2 & 76 & 84 & 189 & 1.80 \\
\hline & 2 & 0.4 & 83 & 105 & 248 & 1.91 \\
\hline & 3 & 0.6 & 95 & 123 & 292 & 2.05 \\
\hline & 4 & 0.8 & 116 & 163 & 325 & 2.29 \\
\hline & 5 & 1 & 151 & 184 & 358 & 2.37 \\
\hline \multirow{5}{*}{ Wet } & 6 & 0.2 & 59 & 77 & 181 & 1.56 \\
\hline & 7 & 0.4 & 68 & 94 & 230 & 1.61 \\
\hline & 8 & 0.6 & 77 & 115 & 252 & 1.75 \\
\hline & 9 & 0.8 & 85 & 136 & 274 & 1.92 \\
\hline & 10 & 1 & 88 & 148 & 296 & 2.02 \\
\hline \multirow{5}{*}{ MQL } & 11 & 0.2 & 57 & 75 & 169 & 1.42 \\
\hline & 12 & 0.4 & 65 & 85 & 191 & 1.59 \\
\hline & 13 & 0.6 & 71 & 94 & 220 & 1.70 \\
\hline & 14 & 0.8 & 76 & 109 & 235 & 1.87 \\
\hline & 15 & 1 & 79 & 129 & 257 & 1.95 \\
\hline \multirow{5}{*}{ Cryogenic } & 16 & 0.2 & 24 & 55 & 62 & 1.31 \\
\hline & 17 & 0.4 & 31 & 69 & 89 & 1.48 \\
\hline & 18 & 0.6 & 37 & 75 & 162 & 1.57 \\
\hline & 19 & 0.8 & 41 & 84 & 183 & 1.71 \\
\hline & 20 & 1 & 44 & 115 & 205 & 1.83 \\
\hline
\end{tabular}

\section{References}

1. World Bank National Accounts Data Manufacturing, Value Added (Current US\$). Available online: https://data.worldbank.org/indicator/NV.IND.MANF.CD (accessed on 29 March 2020).

2. United Nations Sustainable Development Goal. Available online: https://sustainabledevelopment.un.org/ sdg9 (accessed on 29 March 2020).

3. Saad, M.H.; Nazzal, M.A.; Darras, B.M. A general framework for sustainability assessment of manufacturing processes. Ecol. Indic. 2019, 97, 211-224. [CrossRef]

4. Lu, T. A Metrics-based Sustainability Assessment of Cryogenic Machining Using Modeling and Optimization of Process Performance. Ph.D. Thesis, University of Kentucky, Lexington, KY, USA, 2014.

5. Hegab, H.A.; Darras, B.; Kishawy, H.A. Towards sustainability assessment of machining processes. J. Clean. Prod. 2018, 170, 694-703. [CrossRef] 
6. Badurdeen, F.; Shuaib, M.A.; Lu, T.; Jawahir, I.S. Sustainable Value Creation in Manufacturing at Product and Process Levels: A Metrics-Based Evaluation. In Handbook of Manufacturing Engineering and Technology; Nee, A., Ed.; Springer London: London, UK, 2014; pp. 1-28. ISBN 978-1-4471-4976-7.

7. Hegab, H.; Darras, B.; Kishawy, H.A. Sustainability Assessment of Machining with Nano-Cutting Fluids. Procedia Manuf. 2018, 26, 245-254. [CrossRef]

8. Abbas, A.T.; Gupta, M.K.; Soliman, M.S.; Mia, M.; Hegab, H.; Luqman, M.; Pimenov, D.Y. Sustainability assessment associated with surface roughness and power consumption characteristics in nanofluid MQL-assisted turning of AISI 1045 steel. Int. J. Adv. Manuf. Technol. 2019, 105, 1311-1327. [CrossRef]

9. Kishawy, H.A.; Hegab, H.; Deiab, I.; Eltaggaz, A. Sustainability Assessment during Machining Ti-6Al-4V with Nano-Additives-Based Minimum Quantity Lubrication. J. Manuf. Mater. Process. 2019, 3, 61. [CrossRef]

10. Liang, X.; Liu, Z.; Liu, W.; Li, X. Sustainability assessment of dry turning Ti-6Al-4V employing uncoated cemented carbide tools as clean manufacturing process. J. Clean. Prod. 2019, 214, 279-289. [CrossRef]

11. Yip, W.S.; To, S. Sustainable manufacturing of ultra-precision machining of titanium alloys using a magnetic field and its sustainability assessment. Sustain. Mater. Technol. 2018, 16, 38-46. [CrossRef]

12. Mia, M.; Gupta, M.K.; Singh, G.; Królczyk, G.; Pimenov, D.Y. An approach to cleaner production for machining hardened steel using different cooling-lubrication conditions. J. Clean. Prod. 2018, 187, 1069-1081. [CrossRef]

13. Bhanot, N.; Rao, P.V.; Deshmukh, S.G. An Assessment of Sustainability for Turning Process in an Automobile Firm. Procedia CIRP 2016, 48, 538-543. [CrossRef]

14. Yan, J.; Feng, C.; Li, L. Sustainability assessment of machining process based on extension theory and entropy weight approach. Int. J. Adv. Manuf. Technol. 2014, 71, 1419-1431. [CrossRef]

15. Pellegrini, G.; Ravasio, C. A sustainability index for the micro-EDM drilling process. J. Clean. Prod. 2020, 247, 119136. [CrossRef]

16. Khanna, N.; Agrawal, C.; Gupta, M.K.; Song, Q.; Singla, A.K. Sustainability and machinability improvement of Nimonic-90 using indigenously developed green hybrid machining technology. J. Clean. Prod. 2020, 263, 121402. [CrossRef]

17. Moreira, L.C.; Li, W.D.; Lu, X.; Fitzpatrick, M.E. Energy-Efficient machining process analysis and optimisation based on BS EN24T alloy steel as case studies. Robot. Comput. Integr. Manuf. 2019, 58, 1-12. [CrossRef]

18. Du Plessis, J.; Bam, W. Comparing the Sustainable Development Potential of Industries: A Role for Sustainability Disclosures? Sustainability 2018, 10, 878. [CrossRef]

19. Kadam, G.S.; Pawade, R.S. Surface integrity and sustainability assessment in high-speed machining of Inconel 718-An eco-friendly green approach. J. Clean. Prod. 2017, 147, 273-283. [CrossRef]

20. Peralta Álvarez, M.E.; Marcos Bárcena, M.; Aguayo González, F. On the sustainability of machining processes. Proposal for a unified framework through the triple bottom-line from an understanding review. J. Clean. Prod. 2017, 142, 3890-3904. [CrossRef]

21. Li, X.; Wang, K.; Liu, L.; Xin, J.; Yang, H.; Gao, C. Application of the Entropy Weight and TOPSIS Method in Safety Evaluation of Coal Mines. Procedia Eng. 2011, 26, 2085-2091. [CrossRef]

22. Hwang, C.-L.; Yoon, K. Multiple Attribute Decision Making, 1st ed.; Lecture Notes in Economics and Mathematical Systems; Springer-Verlag: Berlin/Heidelberg, Germany, 1981; Volume 186, ISBN 978-3-642-48318-9.

23. Mia, M.; Gupta, M.K.; Lozano, J.A.; Carou, D.; Pimenov, D.Y.; Królczyk, G.; Khan, A.M.; Dhar, N.R. Multi-objective optimization and life cycle assessment of eco-friendly cryogenic N2 assisted turning of Ti-6Al-4V. J. Clean. Prod. 2019, 210, 121-133. [CrossRef]

24. Sivaiah, P.; Chakradhar, D. Effect of cryogenic coolant on turning performance characteristics during machining of 17-4 PH stainless steel: A comparison with MQL, wet, dry machining. CIRP J. Manuf. Sci. Technol. 2018, 21, 86-96. [CrossRef]

25. Shokrani, A.; Dhokia, V.; Newman, S.T. Comparative investigation on using cryogenic machining in CNC milling of Ti-6Al-4V titanium alloy. Mach. Sci. Technol. 2016, 20, 475-494. [CrossRef]

26. Khanna, N.; Agrawal, C. Titanium Machining Using Indigenously Developed Sustainable Cryogenic Machining Facility. In Materials Forming, Machining and Post Processing; Gupta, K., Ed.; Materials Forming, Machining and Tribology; Springer International Publishing: Cham, Switzerland, 2020; pp. 183-205. ISBN 978-3-030-18853-5. 
27. Pušavec, F.; Kopač, J. Sustainability Assessment: Cryogenic Machining of Inconel 718. SV-JME 2011, 57, 637-647. [CrossRef]

28. Froehlich, P. A Sustainable Approach to the Supply of Nitrogen. In Sustainable Approach to Nitrogen; Parker Hannifin Corporation: Haverhill, MA, USA, 2013; p. 4.

(C) 2020 by the authors. Licensee MDPI, Basel, Switzerland. This article is an open access article distributed under the terms and conditions of the Creative Commons Attribution (CC BY) license (http://creativecommons.org/licenses/by/4.0/). 